\title{
Eventos acadêmicos indígenas na UnB sob perspectiva da interculturalidade crítica
}

\section{Indigenous academic events at UnB from the perspective of critical interculturality}

DOI: 10.26512/interethnica.v22i1.11305

\author{
Gabriel Ribeiro Bizerril \\ Universidade de Brasília - UnB \\ e-mail: gabrielribeirob.16@gmail.com
}

Elizabeth del Socorro Ruano Ibarra

Universidade de Brasília - UnB

e-mail: elizabeth@unb.br

\begin{abstract}
Resumo: Passaram-se 12 anos desde o início do convênio entre a Fundação Universidade de Brasília e a FUNAI (2004) que promoveu o ingresso dos indígenas à Universidade de Brasília (UnB). A fim de observar a luta estudantil indígena por direitos dentro da universidade foram analisados quatro eventos organizados por esses estudantes. São eles: o " $1^{0}$ Congresso Brasileiro de acadêmicos pesquisadores e profissionais indígenas" (2009), a " 1 a Semana dos acadêmicos indígenas" (2010), a " 2 a Semana dos acadêmicos indígenas" (2016) e a " 3 a Semana dos acadêmicos indígenas" (2017). Como resultado, afirma-se que esses eventos oportunizam espaços de debate que questionam as assimetrias e o lugar dos indígenas no ensino superior. Também permitem certa visibilidade da persistência dos percalços para a permanência e integração nessa instituição universitária. A pesquisa revela o caráter político da presença indígena na universidade, para quem o diploma universitário representa um instrumento de luta acima de tudo.
\end{abstract}

Palavras-chave: política, direitos indígenas, interculturalidade, ensino superior indígena.

Abstract: It's been 12 years since the beginning of the covenant between Fundação Universidade de Brasília and FUNAI (2004) that had promoted the access of indigenous students in the Universidade de Brasília (UnB). In order to analyse the situation of this students, were observed three mainly events promoted by the indigenous movement: “" $1^{0}$ Congresso Brasileiro de acadêmicos pesquisadores e profissionais indígenas" (2009), the "1 a Semana dos acadêmicos indígenas" (2010), the " ${ }^{\text {a }}$ Semana dos acadêmicos indígenas" (2016) and the " $\mathrm{a}^{\mathrm{a}}$ Semana dos acadêmicos indígenas" (2017). As result it is concluded that these events uses from the political spaces from the university to promote the discussion about the asymmetries and the place of this students in the institution. They also allow certain visibility of the permanence of some problematics in the indigenous presence at the university.

Keywords: politics, indigenous rights, interculturality, indigenous higher education. 


\section{Introdução}

Este estudo analisa os resultados do plano de trabalho "Análise documental do $1^{\mathrm{o}}$ Congresso indígena (UnB -2009) da $1^{\mathrm{a}}$ e $2^{\mathrm{a}}$ semana dos acadêmicos indígenas (UnB - 2010 e 2016)" do projeto de pesquisa "Repertórios de ação política indígena na UnB”, desenvolvido no âmbito do Programa de iniciação científica (PIBIC), edital 2016-2017, da Universidade de Brasília e financiado pelo CNPq e FUB. Foram analisados o $1^{\circ}$ Congresso dos Acadêmicos Indígenas realizado em 2009, a $1^{\text {a }}$ Semana dos Acadêmicos Indígenas de 2010, $2^{\text {a }}$ Semana dos Acadêmicos Indígenas ocorrida em 2016 e a $3^{\text {a }}$ Semana dos Acadêmicos Indígenas de 2017, com o propósito de observar a movimentação dos estudantes indígena na universidade

A pesquisa adotou como referenciais os conceitos de interculturalidade de Walsh (2009), de ação política nos termos de Elizabeth Ruano-Ibarra (2013), os debates sobre a centralidade dos eventos científicos (Targino e Neyra, 2006) como estratégia de divulgação do conhecimento e a noção de campo científico de Bourdieu (1976). Para esta pesquisa também foi fundamental apropriar-se do debate acadêmico em torno da política de cotas, a partir da Lei no 12.711/2012, de modo a facilitar a contextualização dos eventos indígenas realizados na UnB, os quais constituem o objeto de pesquisa.

Entende-se que tais eventos carregam uma ampla bagagem de informações que pode dizer a respeito da organização indígena na universidade, das incongruências institucionais por esses enfrentadas, dos desafios e das propostas de mudança. Foi possível perceber, portanto, os eventos como sendo formas específicas de movimentação dos estudantes indígenas, nos moldes e padrões acadêmicos sem que perdessem a especificidade que fazem desses estudantes, indígenas propriamente ditos. $\mathrm{O}$ artigo foi dividido em cinco partes: uma introdução; o arranjo teórico-metodológico; uma descrição do percurso do movimento indígena no Brasil desencadeando na luta pela participação no ensino superior; a descrição dos quatro eventos em análise; e a conclusão, no qual os eventos são analisados comparativamente.

\section{Arranjo teórico metodológico}

A pesquisa foi feita a partir de análise documental, entrevistas e observação participante. Pode-se falar, portanto, em uma triangulação metodológica aos termos de Duarte (2009, p. 3). A triangulação é uma combinação de métodos que quebra com a ideia de paradigmas metodológicos estáticos. Tal estratégia "[...] não representa um conceito metodologicamente integrado, mas uma metáfora com um vasto campo semântico”. (Ibid, p. 3 - 4)

Essa abordagem questiona a dicotomia estabelecida entre a epistemologia positivista que preza pela análise quantitativa, tendo uma teoria definida que irá conduzir a interpretação dos fenômenos, através da análise de dados empiricamente observáveis. Nesse caso, o controle da investigação ganha centralidade. De outro lado, tem-se a abordagem da epistemologia construtivista, que se apoia principalmente na análise qualitativa, na qual a teoria se desvenda com o decorrer do trabalho de campo (Duarte, 2009). 
Como se sabe, a própria experiência empírica conduz a uma determinada teoria, o que não significa que não se tem base em teorias antes da realização da pesquisa de campo. A opção pela triangulação, por não fazer uso exclusivo do qualitativo ou quantitativo, possibilita diferentes formas de olhar a realidade. Não se trata de uma validação promovida pelo uso de diferentes métodos, mas sim a ampliação da compreensão do objeto de estudo, neste caso dos eventos indígenas realizados na UnB nos anos 2009, 2010, 2016 e 2017.

A compreensão dos eventos passou pelo prisma de quatro referenciais teóricos. Por se tratar de um movimento no qual os estudantes indígenas formam um grupo coeso que possuem proximidade temporal-espacial, agindo dentro de um local bem delimitado e sendo as implicações da ação comum a todos membros desse corpo, utilizei-me do conceito de ação-coletiva (RUANO-IBARRA, 2013). Os eventos ocorrem dentro da universidade, e, portanto, imbricado nas relações específicas do campo científico, sendo essa parte analisada a partir de Bourdieu (1976).

O entendimento da forma como um evento científico é estruturado teve como base as discussões de Neyra e Targino (2006) sobre comunicação científica. Tendo em vista se tratar de um fenômeno intrinsicamente intercultural, a inserção indígena na universidade foi compreendida a partir do conceito de interculturalidade crítica de Catherine Walsh (2009).

A análise do $1^{\circ}$ Congresso dos acadêmicos indígenas (2009) se fundamentou na pesquisa documental, construída a partir da análise da carta circular emitida pelo Centro Indígena de Estudos e Pesquisa (CINEP1), (LUCIANO, 2009); pela programação oficial do evento e por áudios da relatoria do evento. Esse corpo documental foi analisado de forma crítica e pragmática, tendo em vista cinco dimensões propostas por Cellard (2008): 1) Contexto, 2) O autor ou autores, 3) A autenticidade e a confiabilidade do texto, 4) A natureza do texto e 5) Os conceitos-chave e a lógica interna do texto.

A descrição analítica da $1^{\mathrm{a}}$ Semana dos acadêmicos indígenas (2010) se apoiou nas narrativas obtidas nas entrevistas com estudantes indígenas. Essa técnica de coleta de dados se mostra importante justamente por tornar possível acessar a informações indisponíveis em outras fontes. Reconhecida sua importância ímpar para a pesquisa nas ciências sociais a entrevista permite a "[...] obtenção de dados referentes aos mais diversos aspectos da vida social", sendo seus resultados "suscetíveis de classificação e quantificação" (GIL, 1999, p. 115).

A compreensão da $2^{\mathrm{a}}$ e $3^{\mathrm{a}}$ Semanas dos Acadêmicos Indígenas (2016 e 2017 respetivamente) se nutriu principalmente da observação participante. Tive a oportunidade de participar desses eventos como ouvinte, podendo observar de perto as especificidades, tensões e relações. A importância da observação nas ciências sociais foi destacada por Neuma Aguiar (1978) quando afirmou que

\footnotetext{
1 Surgiu na década de 2000 sob a liderança do antropólogo indígena Gersem dos Santos Luciano, do povo Baniwa, na época doutorando do Departamento de Antropologia (DAN) da UnB.
} 
uma das vantagens dessa técnica é a profundidade dos dados, que permite atingir melhores níveis de compreensão dos fatos sociais em questão.

\section{Estudantes indígenas nas universidades brasileiras}

A presença dos estudantes indígenas nas universidades brasileiras remete a um processo que, inegavelmente, encontra suas raízes na dinâmica de colonização portuguesa. A assimetria de poder estabelecida desde a chega ao "novo mundo" instaurou um plano de relações de um "novo padrão de poder" (QUIJANO, 2005, p. 117). Segundo Quijano (2005), fez parte do controle dessas novas populações pelos europeus a constituição de uma epistemologia que inferiorizava social e biologicamente os povos conquistados. Esse 'padrão' ganha base institucional no Brasil a partir da república, quando se houve uma intenção de unificar e, por assim dizer, federalizar esse território recém delimitado politicamente. No sentido de fomentar a assimilação dos povos indígenas ao projeto de um Estado Nacional, foram implementadas políticas buscando a homogeneização para se consolidar como um país coeso. As diferenças tinham que ser suprimidas por um "propósito maior". Falava-se de uma identidade nacional, como argumento e justificativa para dizimar as diferenças.

Quando não 'assimilados' eram invisibilidades como mostra a historiografia brasileira. Em 1844 foi publicado o trabalho de Karl Friedrich Philipp von Martius, "Como se deve escrever a história do Brasil.", vencedor do concurso do na época Instituto Histórico e Geográfico Brasileiro. Em sua obra, assume o país como sendo um local de encontro de raças, a saber o branco (português), os indígenas e os negros, que parte da mestiçagem, porém evidenciando a suposta superioridade do português sobre as demais. O indígena, especificamente, era visto como um povo 'degenerado' e 'desintegrado' já antes da ocupação portuguesa, negando a histórica cultural desses povos.

Von Martius propunha um trabalho 'etnográfico', baseado na observação direta e, principalmente, no estudo da língua, visto como o "documento mais geral" e "significativo". Compartilhando das idéias de degeneração do homem americano, defendidas, sobretudo, por Buffon e De Pauw, von Martius acreditava que os índios brasileiros constituíram resquícios de uma antiga civilização, contando com um número bastante reduzido no momento do contato com os europeus, o que facilitara a conquista (RODRIGUES, 2007, p. 4).

A situação se perdura até hoje, gerando muitos maus entendidos e perpetuando uma imagem do indígena ainda sob um espectro colonial.

A relação com os indígenas em todas as esferas (social, política, cultural, simbólica e econômica) se deu nesse sentido. Tentou-se a todo custo integrá-los à lógica da "nação". A ideia era “civilizá-los" mediante um processo de integração extremamente violento. Nesse sentido, em 1910, foi fundado o Serviço de Proteção ao Índio (SPI), que surgiu com uma proposta tutelar de integrar os indígenas à sociedade brasileira. Tratou-se da primeira preocupação burocrática e legal por parte do governo brasileiro voltada aos indígenas, 
inserido no contexto de expansão das fronteiras do território nação e dos conflitos que ocorriam com os indígenas no sertão, dentro de um projeto humanista baseado nos preceitos positivistas, encabeçado pelo general Rondon (RIBEIRO, 1975).

A partir de então, eles serão vistos como juridicamente incapazes, e, portanto, tendo o Estado como seu responsável. O plano era aliá-los à lógica econômica capitalista, transformando-os em mão de obra no campo ou trabalhadores em centros urbanos. Ulteriormente têm-se a Lei 6001 de 1973, conhecida como Estatuto do Índio, ainda vigente apesar do seu caráter inconstitucional a partir da reforma de 1988, e a criação da Fundação Nacional do Índio (FUNAI). O Estado assume um papel claramente tutelar, "cuidando" do indígena e tomando decisões por ele. A educação era feita no sentido de adaptá-los à lógica dominante. Basta lembrar que por muito tempo a igreja ficou encarregada da educação e, não obstante, catequese indígena (KAHN e FRANCHETTO, 1994; LUCIANO, 2009).

A partir dos anos 70 os movimentos indígenas apoiados por organizações nãogovernamentais (ONGs) começam a ganhar maior expressividade passando a tornar-se assunto na agenda do governo. O grande marco desse processo foram os direitos conquistados e reconhecido na Constituição de 1988. Além de modificações no ensino, ao incluir a língua originária dos povos no currículo escolar, essa reforma constitucional foi um marco para a demarcação das terras indígenas e direitos territoriais. Sem contar o reconhecimento da participação ativa dos povos indígenas nas decisões que os concernem. Mas o maior efeito foi a quebra da legitimidade da tutela estatal. A constituição abriu espaço para maior atuação em defesa dos direitos dos indígenas, sejam demandados por eles propriamente ditos ou dos indigenistas organizados em ONGs (KAHN e FRANCHETTO, 1994; LUCIANO, 2009).

Como resultado dessas mudanças, começou a ter uma demanda maior por vagas para povos indígenas no ensino superior. A necessidade de uma graduação se aliava a própria emancipação indígena, que visa, na legitimidade adquirida pela academia, uma forma de adquirir espaço na hora de conquistar e reivindicar direitos. A graduação dos indígenas é elemento central na quebra da perspectiva tutelar. No início dos anos 90 estimavam-se 200 alunos indígenas no ensino superior. Já no começo dos anos 2000 esse número expandiu para 1200 (SOUSA, 2009). Isso dá conta de como o processo está em constante aceleramento.

O ingresso dos indígenas nas universidades brasileiras nessa época de meados dos anos 2000 era ainda muito confuso, sendo que cada Estado da Federação possuía suas próprias regras. Apesar da FUNAI fazendo a mediação entre as partes e o MEC subsidiando financeiramente os programas de ingresso para indígenas, alguns desafios novos foram desvendando-se. A presença recente dos indígenas no ensino superior evidenciava a urgente necessidade de uma política nacional coesa e bem estruturada (SOUSA, 2009). 


\subsection{Os indígenas na UnB}

Nesse mesmo contexto, foi estabelecido em 2004 o convenio FUNAI - FUB (Fundação Universidade de Brasília). "Este convenio FUNAI/FUB-UNB, previu aproximadamente a inclusão de 200 estudantes indígenas, em diferentes áreas do conhecimento, no período de 10 anos com recursos locados da FUNAI" (SOUSA, 2009, p. 28). O objetivo, em termos do indicador quantitativo não se concretizou, porém, o projeto foi pioneiro no âmbito de uma universidade federal, o que demonstrou uma preocupação maior com a causa.

O que se propôs a partir desse convenio foi acesso à universidade acompanhado de um auxílio financeiro de $\mathrm{R} \$ 900,00$ e acompanhamento específico dos estudantes ingressos pela UnB. Esse auxílio é mantido conforme o desempenho do estudante na universidade, sendo cortado em caso de reprovação de matéria ou caso as menções estejam abaixo do esperado. Logo, estudantes que vinham de um sistema educacional deficitário, em uma realidade muitas vezes radicalmente diferente da qual se deparam na UnB, foram submetidos a critérios avaliativos que conduzem a perda, em muitos casos, da única fonte financeira de permanência na universidade (REIS e EUZEBIO, 2012)

Em um segundo momento tem-se a elaboração de um vestibular específico indígena, que teve seu primeiro edital em 2006. "Esse processo tem como característica que a escolha do curso deve ser feita pelas comunidades, com o objetivo de, após formado, contribuir para com suas regiões de origem" (REIS e EUZEBIO; 2012, p. 8).

Em 2012, a Lei 12.711 é promulgada e têm-se uma reviravolta na ocupação do espaço universitário por minorias sociais e étnicas. Ela ampliou consideravelmente o acesso à universidade. Muda-se o panorama, que deixa de ser restrito a algumas exceções e passa a ser realidade na maior parte do país. Com isso, novos desafios e dificuldades. A inserção dos estudantes indígenas gera incoerências, principalmente no que tange à inadequação das formas de conhecimento em que os dois grupos estão inseridos, e se depara com diversos empecilhos, tal como a falta de suporte financeiro e assistencial.

Em 2017, o Centro de Seleção e de Promoção de Eventos Universidade de Brasília (Cespe), instituição responsável, dentre outros concursos, pelas provas de admissão na UnB) anuncia a volta do vestibular específico indígena, que estava sem ser realizado a três anos. Em comunicado no site oficial é apresentado que haverá vestibular específico para povos indígenas no $1^{\mathrm{O}}$ e $2^{\mathrm{O}}$ semestre de 2018, sendo resguardadas 72 vagas nas áreas de Administração, Ciência Política, Ciências Sociais, Comunicação Organizacional, Direito (diurno e noturno), Enfermagem, Engenharia Florestal, Fisioterapia, Gestão Ambiental, Gestão do Agronegócio (diurno e noturno), Jornalismo, Licenciatura em Ciências Naturais (diurno e noturno), Medicina, Nutrição, Psicologia, Saúde Coletiva e Serviço Social. 


\section{Descrição dos eventos}

Os eventos acadêmicos indígenas seguem a práxis de divulgação do conhecimento problematizada por Targino e Neyra (2006). Porém, o que chama atenção é que apesar de serem concebidos como eventos acadêmicos, sua centralidade não é esse compartilhamento de informações com uma comunidade científica específica. A estrutura acadêmica (como os debates, palestras e mesas redondas) é utilizada para legitimar a reinvindicação de causas comuns aos estudantes indígenas. Como afirma Ruano-Ibarra (2013), esses eventos são uma forma específica de manifestação de uma ação coletiva dos estudantes indígenas da universidade.

O formato acadêmico é uma busca pelo que Bourdieu chamou de "competência científica", sendo "compreendida enquanto capacidade de falar e de agir legitimamente (isto é, de maneira autorizada e com autoridade), que é socialmente outorgada a um agente determinado" (BOURDIEU, 1976, p. 1). O dito campo científico é embreado por disputas de poder e influências de outros campos. A busca da legitimidade acadêmica pelos estudantes indígenas é, nesse caso, apenas mais uma forma de manifestação de um campo específico que possui suas pautas e intenções (no caso, o movimento indígena). Logo, os eventos são estruturados em mesas, debates, rodas de conversa, dentre outros formatos, justamente porque essa estrutura tem sido historicamente ratificada pela sua "competência" e contribuição com o rigor exigido do trabalho científico.

A análise revelou que cada evento carrega um aspecto central que varia de acordo com o cenário político e as pautas dos movimentos indígenas do momento, mantendo uma continuidade sobre a problemática da inserção e integração dos estudantes indígenas no meio acadêmico. Dessa forma, a análise dos eventos se apresenta cronologicamente na seguinte ordem: 1) Primeiro Congresso dos Acadêmicos Indígenas (2009); 2) Primeira Semana dos Acadêmicos Indígenas (2010); 3) Segunda Semana dos Acadêmicos Indígenas (2016); 4) Terceira Semana dos Acadêmicos Indígenas (2017).

\section{1. $O 1^{\circ}$ congresso dos Acadêmicos Indígenas}

Esse congresso foi promovido pelo CINEP e pela Articulação dos Povos Indígenas do Brasil (APIB ${ }^{2}$ ). É de suma importância destacar o protagonismo indígena na organização, pois esse evento possui como intrínseca característica o levantamento de pautas políticas do movimento indígena em relação ao direito à educação. A idealização desse evento se entende como sintomática de uma situação problemática e da agência dos indígenas na procura por mudanças.

O evento objetivou fomentar discussões em um espaço aberto e plural entre, principalmente, profissionais e indígenas ingressos no ensino superior, a fim de gerar uma proposta para uma política voltada para ensino superior indígena que seria apresentada ao Estado brasileiro. À época do evento (2009) ainda não

${ }^{2}$ A APIB, surgiu em 2005 como fruto do Acampamento Terra Livre (ATL), e tem atuado até hoje pela promoção e defesa dos direitos indígenas. 
havia a Lei $\mathrm{n}^{0} 12.711$ de 2012 ou Lei das Cotas, situação que se desdobrava em acesso à universidade ainda mais precário para os povos indígenas.

Foi composto por uma conferência de abertura; cinco mesas redondas; 13 eixos de grupos temáticos; "projeção de filmes, apresentação de música, dança, e outras manifestações" (CAI, 2009, p. 5). Essa composição temática é um fator a se destacar, pois mistura a tradição técnico-científica, típico de um evento acadêmico, com as manifestações culturais, próprias dos movimentos indígenas. Os temas e os respectivos coordenadores dos grupos foram:

\section{Artes e técnicas}

Coordenadora: Maria Auxiliadora C. da Silva (Fundação de Apoio à Pesquisa do Estado do Amazonas-Fapeam)

\section{Histórias e memórias}

Coordenador:Daniel Munduruku (Inbrapi)

\section{Saúde}

Coordenadora: Carla Costa Teixeira (DAN/UnB)

\section{Direitos}

Coordenadores: Vilmar Guarani (Cinep)

Rodrigues Pinto (Ceppac/UnB)

\section{Línguas}

Coordenadores: Edílson Baniwa (SGC)

Maná Kaxinawá (UnB)

6. Gestão territorial e etnodesenvolvimento

Coordenador: Henyo Barreto (IEB)

\section{Agricultura e meio ambiente}

Coordenador: Olavo Wapichana (UnB)

\section{Identidade e diversidade}

Coordenador: Stephen Baines (DAN/UnB)

\section{Comidas}

Coordenadora: Maria Eunice Maciel (UFRGS)

\section{Músicas}

Coordenador: Edmundo Pereira (UFRN)

\section{Espiritualidade}

Coordenador: Marcos Terena (Memorial dos Povos Indígenas)

12. Vida nas cidades

Coordenadores: Cristhian T. Silva (Ceppac/UnB)

Juliana Melo (DAN/UnB)

\section{Educação}

Coordenadora: Francisca Novantino Pareci (Instituto Maiwu)

Nos Grupos Temáticos percebe-se com muito mais clareza a busca por uma perspectiva intercultural no evento. É interessante o uso dessa ferramenta por 
se apresentar de forma versátil, pois possibilita, através da divisão de grupos contendo cada um determinado tema, a discussão de um número variado de temas. Isso encaixa-se bem com a proposta do evento de trocas de conhecimentos levando-se em conta as trajetórias e vivências dos participantes, tanto na universidade como fora dela, dando legitimidade para um conhecimento que não é tido tradicionalmente como científico sobre assuntos diversos.

A finalidade foi que durante as doze horas de evento os participantes discutissem suas experiências na universidade, destacando os problemas e dificuldades e abrindo possibilidades de enfretamento dessas questões. Logo, o conhecimento de várias pessoas de distintas áreas estará em consonância com o tema proposto e com as pesquisas dos acadêmicos indígenas, gerando um verdadeiro debate intercultural e inter científico. Isso é possível pelo cuidado da escolha dos temas que permitem tanto os acadêmicos como os sabedores tradicionais indígenas em darem seus pontos de vista. E toda essa proposta inserida em um modelo de evento científico uma vez que toda reunião conta com um coordenador e relator, para que a informação seja organizada e sistematizada. Acredito que essa parte seja essencial para o entendimento da proposta dos eventos: intercultural, pois o conhecimento discutido é plural, indígena e científico.

A vivência dos participantes é enfatizada pois essa servirá para fomentar a troca de conhecimentos e experiências entre os integrantes do grupo. A intenção dos grupos era gerar trocas de conhecimentos, sem que esses sejam valorados segundo um currículo ou notas acadêmicas, mas sim dando valor e importância para as mais variadas formas de vivência. Essa perspectiva remete ao debate acadêmico sobre interculturalidade crítica e funcional (Walsh, 2009) e reforça os objetivos do congresso: "compartilhar experiências no âmbito acadêmico, identificando as dificuldades e contornando-as a partir dessa frutífera troca” (Programação $1^{\circ}$ Congresso dos acadêmicos indígenas, 2009, p. 5).

Quanto às manifestações culturais indígenas, elas compõem o terceiro componente metodológico do congresso. Houve "projeção de filmes, apresentação de música, dança, e outras manifestações" (Programação $1^{\mathbf{o}}$ Congresso dos acadêmicos indígenas, 2009; p. 5). Se tratando de um evento acadêmico dos povos indígenas brasileiros, essas manifestações são de extrema importância pois aproximam a universidade das expressões culturais características de cada povo e poderia impactar no (re)conhecimento da sua diversidade dentro da instituição.

Os organizadores do evento enfatizaram durante a convocação do congresso que "as dinâmicas devem levar ao conhecimento mútuo, à sistematização dos interesses, perspectivas, preocupações, modos de viver e pensar os temas e questões enfocados pelos grupos temáticos" (Programação $1^{0}$ Congresso dos acadêmicos indígenas, 2009; p. 5). Dado o objetivo do congresso, esse evento permitiu a manifestação coletiva dos indígenas tornando-as demandas políticas. O espaço é usado para dar fala aos estudantes e, a partir de suas experiências, são levantadas reinvindicações de melhoras direcionadas a esses estudantes e profissionais e demais participantes. 
Através das mesas e dos debates suscitados propõe-se uma abordagem intercultural que leve os conhecimentos indígenas a par de igualdade com o conhecimento científico da sociedade moderna ocidental. O questionamento do currículo tradicional é chave nessa abordagem, assim como também é o ingresso, que exige uma diferenciação do processo educacional padrão da universidade.

Esse espaço reforça também a união dos estudantes indígenas e o compromisso desses para com seus respectivos povos. O objetivo indígena no ensino superior não é exatamente similar ao pretendido pelos estudantes urbanos e sem engajamento étnico. Há um histórico de resistência e luta por detrás disso que não deve ser esquecido, mas sim reiterado. Ou seja, as discussões são direcionadas para o povo indígena assim como para a sociedade não indígena. Não se pode perder de vista que a presença indígena em uma universidade é também política, fruto de um histórico de luta e resistência.

Niederauer (2013) corrobora essa análise na sua análise de sites indígenas em comparação com o portal da UnB. A autora coloca em evidência a exclusão textual nos anúncios do portal institucional, em que os atores sociais são apagados ou suprimidos do contexto noticiado colocando-os em segundo plano, operando estratégias de encobrimento. O site institucional "nominaliza", diminui o autor da notícia à uma categoria nominal sem prestar a devida referência.

Segundo Marcia Niederauer (2013), no portal da UnB utilizada a ativação e passivação como estratégias de representação de atores sociais. Os estudantes indígenas só são ativos quando realizam apresentações culturais, enquanto seu lugar nos debates é omitido outorgando-lhes um lugar passivo. Essa constatação demonstra como a universidade exotiza os indígenas, reforçando a imagem mitificada e essencializada. Desse modo, nessas notícias os discentes indígenas são "outsider", enquanto as atividades acadêmicas são sempre de mérito dos agentes brancos. Coloca-se uma relação de consentimento, onde a presença indígena na universidade parece atribuída à permissão da hegemonia branca.

Os eventos, como já mencionado, possuem, acima de qualquer intenção, um caráter político, mobilizador, em prol da reivindicação de direitos que proporcionem o acesso e a permanência dos estudantes indígenas nas universidades.

\subsection{A 1 a Semana dos Acadêmicos Indígenas}

Este evento foi realizado em abril de 2012. Na época os estudantes indígenas da UnB se agrupavam na Associação Indígena do Distrito Federal (AIDF) e tinham como espaço de encontro uma sala localizada no subsolo do Instituto Central de Ciências (ICC), ala norte, autodenominada Centro Acadêmico Indígena (CAInd). Foi através dessas duas nomenclaturas que eles organizaram a " 1 a Semana dos Acadêmicos Indígenas”. Trata-se, portanto, do primeiro evento organizado integralmente por estudantes indígenas já ingressos na UnB.

As minhas percepções do evento foram baseadas primeiramente em duas entrevistas realizadas com dois estudantes indígenas que participaram do 
evento, a saber Suliete Gervásio e Porã Potiguara respectivamente, e em notícias de promoção do evento encontradas na internet. Não foi possível ter acesso a documentos sobre o evento, uma vez que na época o Centro de Convivência Multicultural dos Povos Indígenas da Universidade de Brasília, Maloca, atual local de arquivamento de documentos relacionadas às atividades dos indígenas na universidade não existia, e na Diretoria de Diversidade da UnB (DIV) não há nenhum registro formal do evento.

A necessidade se dava, como aponta o estudante indígena Humberto Porã, do povo Potiguara, na busca por visibilidade dentro da universidade:

$O$ inicial era despertar o interesse da comunidade acadêmica. Trazer mais um debate em relação ao ingresso à permanência dentro da universidade. E propiciar uma aproximação. Tinha uma galera vendendo artesanato no ICC o tempo todo, no RU. $O$ objetivo era então estabelecer um diálogo entre os indígenas e a comunidade acadêmica.

Como o próprio Porã disse, na época, o maior empecilho para os estudantes era a não aceitação ou, melhor, o dessaber dos demais estudantes: "A UnB sempre preza pela diversidade e multiculturalidade. Você acredita que, na prática, existe essa multiculturalidade?"

A uma vontade de fazer de fato a multiculturalidade existir. $O$ que eu vejo assim não é bem a UnB por si só né, a administração, eu culpo mais os alunos mesmo, por não ter abertura por não permitirem. Na recepção dos calouros se fala de nos apresentarmos lá, muitos me procuraram já, mas muitos alunos indígenas viajam e só voltam em cima do começo das aulas. Então assim, para uma semana antes fica pouco viável. Mas a falha mesmo acredito é das pessoas que não se permitem o contato com essa diversidade.

A resposta não era para ter me causado espanto, uma vez que reflete justamente o modo como a sociedade brasileira trata os indígenas. Isso tornou-se ainda mais claro depois que perguntei "Como foi a recepção da comunidade acadêmica?”

Vou te dizer que foi fria, inicialmente. O Brasil é muito estranho em relação ao indígena, prefere ignorar do que ir lá ver. Tivemos um público bom, mas comparado com a quantidade de alunos na UnB foi fria.

As problemáticas enfrentadas por esses estudantes são postas no dia a dia, na informalidade do cotidiano e não somente pelos entraves da instituição. $O$ evento é uma forma de se reafirmar em um espaço renegado historicamente. São locais elitizados por excelência, no qual apenas uma parte da população é aceita e pode desfrutar de seus benefícios. O conhecimento exigido para o ingresso e permanência acabam operando como formas de assegurar a exclusividade de acesso à universidade a apenas uma parcela privilegiada da população. Isso para estudantes que partem de tradições culturais muito 
diversas, educados muitas vezes em instituições de ensino básico deficitárias, se torna um grande empecilho.

Além disso, pesa sobre esses estudantes o estranhamento no meio acadêmico dos não-indígenas. A historiografia nos prova, que o que se pensa do indígena é algo ainda muito longe da realidade, partindo de uma perspectiva racista e ainda colonial.

O evento é justamente uma forma de superar tal entrave, proporcionando contato direto entre os estudantes, para que haja uma maior aceitação e uma convivência mais sadia seja estabelecida.

Contribuindo para esse indicativo, quando fiz a seguinte pergunta para Porã: “Em um balanço geral, quais resultados foram obtidos do evento?”.

Olha, a visibilidade. Nós conseguimos de certa forma visibilidade dentro do espaço. As pessoas não buscam conhecerem, mas pelo menos a partir de então passaram a saber que existe. Esse passo a gente conseguiu avançar já, faltam os outros.

Não à toa a manchete sobre o evento no site oficial da UnB foi o seguinte: "Tradição indígena ensina comunidade acadêmica a lidar com diferenças". Na matéria, as falas dos indígenas deixam claras suas intenções: mostrar para a comunidade acadêmica o que é ser indígena, como sendo algo constitutivo do ser e não como uso de adornos ou vestimentas características, como a visão que os pinta de exóticos tende a mostrar.

O imaginário popular, como é bem sabido, tende a representar os indígenas no singular e no passado. O dia 19 de abril, "Dia nacional do Índio", é um ótimo exemplo disso. Como aponta a estudante indígena Suliete Gervásio, do povo Baré, em resposta à pergunta “Quais foram os objetivos do evento?”:

Foi de reinvindicação mesmo, e não só dizer que o dia do índio é dia 9 de abril, mas mostrar para universidade que a gente está aqui e que dia do índio são todos os dias. O objetivo maior era mostra que na universidade tinham estudantes indígenas $e$ quebrar um pouco esse pensamento de que índio é só o índio do estereótipo do Xingú ou do Norte, mas mostrar também a outra diversidade dos indígenas do nordeste.

Um momento bem marcante do evento foi no primeiro dia, em uma performance de Olavo Wapichana, como aponta Porã. A minha pergunta tinha sido “Teve elaboração de documento?", mas dado a irrelevância de uma sistematização documental para o evento em si, já que nada influi para os objetivos do evento, sua resposta foi:

Documento final não teve. Foi mais uma proposta de uma conversa solta, não teve tanta reinvindicação formal. Tanto que o ato dizia "não ao preconceito, a UnB é multicultural". E foi bem interessante na abertura da semana, o ato que a gente fez no $R U$, o Olavo, que é indígena, estava vestido de paletó. Do nada foi tirando a roupa dele e ele ficou a caráter, com roupa de palha e 
tudo mais. Foi muito simbólico para nós, quer dizer, tirar a capa e mostrar quem você é.

Um elemento muito interessante é o impacto que o evento causa nos próprios indígenas.

Eu estava recém-chegada na verdade e como todos os estudantes que vem do interior mesmo fiquei mais recatada. Fiquei mais observando mesmo. Observando no sentido de não fazer perguntar nem nada, mas eu participei eu estava lá na oficina de pintura, observando e aprendendo.

“E o que você achou de ter um evento dos acadêmicos indígenas?” - Perguntei.

Assim, eu vou falar a verdade. Eu até chegar aqui, antes de eu chegar em Brasília, não me afirmava como indígena, porque capital mesmo que eu conhecia era só Manaus. Então não há essa discussão ou questionamento se eu sou índia se sou isso ou aquilo, porque lá todo mundo é igual né, a gente sabe o que é, então não há esse questionamento ou essa demanda não, de você mostrar para os outros quem você é, entendeu? E quando eu cheguei aqui achei tudo muito diferente, porque, por exemplo, o Porã que é nordeste já vinha de movimentos indígenas, ele participou de movimentos jovens lá na comunidade dele. E eu não, eu não participava. Só meu tio que fazia parte da associação indígena, que até hoje ele faz parte. E eu não, então assim eu fui conhecendo aos poucos e para mim foi uma coisa muito nova. Eu aprendi muito, eu sou uma pessoa totalmente diferente da de quando eu cheguei. Amadureci muito com o conhecimento de outros povos indígenas, de língua, cultura, e política né, que a gente teve que fazer vários movimentos para conseguir, que hoje a gente tem a Maloca esse espaço de conquista, que é referência que a gente sempre fala. Tivemos que faltar algumas aulas por causa de reuniões, e fazer isso e aquilo. E estamos ai!

Ou seja, o evento serviu também para estimular uma identidade coletiva em torno do termo político "indígena”. Isso não significa que todos os indígenas se identifiquem como iguais, mas que frente ao Estado, por enfrentarem situações análogas, utilizam-se do termo como forma de ganhar força política. $O$ evento faz parte, portanto, de uma movimentação indígena de auto identificação coletiva para enfretamento de situações problemas partilhados entre seus componentes.

Foram dois dias de reconhecimento da tradição indígena, de debates e afirmação dentro do espaço. Perguntei a Porã, então, "Qual seu respaldo pessoal do evento?"

Talvez o sentimento de missão cumprida, teoricamente. Ou missão para ser cumprida que já iniciou. Você chega e vem no sentido do "pó, estou aqui não sou visto, não sabem que eu existo, como faço para que me enxerguem tal como sou?”, e então eu 
acho que fixa esse sentimento de que já começam enxergar começam a ver que existe um grupo diferente, com suas peculiaridade, acho que isso é o que fica por enquanto. E que temos muito que lutar ainda. O sentimento maior que fica é mais esse, que a luta é grande, para se almejar de fato esse reconhecimento dentro da universidade.

Foi um pontapé inicial dado pelos estudantes indígenas, que reconheceram a necessidade de uma movimentação para serem vistos dentro da UnB. A continuidade dessa movimentação pode ser vista nos outros eventos, onde novas pautas de lutas são propostas e as antigas reforçadas.

Assim como no evento antes descrito, as atividades também estiveram distribuídas em diferentes locais do Campus Darcy Ribeiro (UnB), mais especificamente no Restaurante Universitário e no ICC. A agenda do evento incluiu três Mesas de Debate; uma passeata com apresentação de banner e discussões no RU; oficina de pintura corporal; apresentação e comercialização de comidas típicas e artesanato étnico e exibição de danças e performances artísticas.

Foi o primeiro evento acadêmico indígena, idealizado e organizado somente por estudantes indígenas da UnB, que se utilizaram da estrutura de eventos acadêmicos para debater os problemas referentes à inserção indígena nessa universidade. Nesse caso, a maior pauta veiculada durante o evento foi a visibilidade dessas questões no campus universitário. O objetivo almejado foi, portanto, fazer com que a presença indígena na universidade fosse mais bem compreendida pela comunidade universitária não indígena.

\subsection{A 2a Semana dos Acadêmicos Indígenas}

A $2^{\text {a }}$ Semana dos Acadêmicos Indígenas da UnB foi realizada no âmbito da comemoração do dia do índio, em abril de 2016, organizada pela Associação dos Acadêmicos Indígenas da UnB (AAIUnB), e desenvolvida no Centro de Convivência dos Povos Indígenas (Maloca-UnB)3. Inaugurada em dezembro de 2014, confere uma qualidade diferenciada a esse evento.

A Maloca-UnB planejada e construída por demanda dos estudantes indígenas constitui uma referência para esses povos na universidade. Não é coincidência, portanto que o acesso para os documentos da $2^{\mathrm{a}}$ Semana tenha sido viabilizado, pela existência do arquivo institucional da Maloca. Além disso, o centro de convivência torna possível a concentração das atividades em um local fixo.

O evento durou uma semana e teve quatro Mesas de Debate; uma Roda de conversa; performance no RU com passeata, apresentação de banner e discussões; exibição de um filme e debate; apresentações culturais diversas danças; cantos; oficinas de pintura; de artesanato e comidas típicas. Possuiu como justificativa central o não cumprimento do plano acordado com $o$ convênio FUB/Funai de 2004, que propôs formar e qualificar pelo menos 200 especialistas indígenas em 10 anos. Após 12 anos de acordo firmado foram 114

${ }^{3}$ Sobre a conformação e trajetória da Maloca e da AAIUnB ver Miranda (2017). 
estudantes qualificados. Além disso, questiona-se a visibilidade desses estudantes na universidade, tal como na $1^{\text {a }}$ Semana. Muitas vezes passam despercebidos, sem que o meio acadêmico os dê muita atenção. Logo, entra na pauta o ingresso, a permanência e os desafios desses estudantes.

O público alvo foram os "Estudantes, servidores e professores da Universidade de Brasília, acadêmicos indígenas, lideranças indígenas e pajés, artesãos indígenas" (Projeto da II Semana cultural dos povos indígenas na UnB, 2012; p. $5)$.

Dessa forma, temos que o objetivo geral do evento é o debate a respeito do ingresso, permanência e os desafios enfrentados pelos estudantes indígenas, além da visibilidade para o movimento estudantil indígena, proporcionando reconhecimento de seus saberes e tradições. Ao todo foram listados cinco objetivos específicos: "1) Promover debates para discutir a política de ações afirmativas, os avanços, perspectivas e desafios dos estudantes indígenas na Universidade de Brasília"; "2) Realizar oficina de pinturas corporais no decorrer do evento"; 3) "Realizar exposição de artesanatos, documentários, filmes e painéis sobre cada povo indígena presente na UnB"; 4) "Apresentar danças culturais indígenas"; 5) "Realizar momento espiritual". (Projeto da II Semana cultural dos povos indígenas na UnB, 2012; p. 5 - 6). Portanto percebe-se que o evento é uma mobilização dos estudantes em torno da denúncia e questionamentos das problemáticas da inserção indígena na UnB, em formato de evento científico (uma vez que é a comunicação científica que tem legitimidade dentro do ambiente acadêmico) porém com as especificidades do movimento, sendo, dessa forma, um espaço de trocas de conhecimentos interculturais.

Para além dos problemas enfrentados dentro da universidade existe um outro peso que esses estudantes têm que carregar, baseado nas relações com a família e a comunidade. Coloca-se um cargo muito grande em cima deles, uma responsabilidade que parte das comunidades indígenas a qual esses devem um retorno. Indaga-se: "O que é formação para o indígena na universidade? Como tratar de tais questões para os indígenas? Nos estudos da área da saúde, como perceber e respeitar os costumes dos indígenas em certas situações? (APURUNÃ; et al. p. 5).

É nesse sentido que o evento entra como uma forma de resistência desses estudantes, uma vez que demanda por adequações institucionais e melhorias da qualidade de vida. E como uma forma de aproximação entre eles, que fortalecem um vínculo solidário a partir da troca de experiências e vivências de um com os outros.

Em sua fala no evento, a Coordenadora das questões indígenas da Maloca/UnB, Cláudia Regina, destacou a diversidade e pluralidade desse grupo. A falta de suporte financeiro do estado só agrava uma situação delicada. Um grande exemplo disso é o fato de que a bolsa do convenio FUB-UnB se mantém, mas não há auxílio para deslocamento. Ela diz ainda sobre um Grupo de Trabalho organizado por alunos da graduação da pós e professores, que possui como foco a elaboração de mediadas que garantissem a permanência e boa convivência dos 
estudantes dentro da universidade. Essa não se responsabiliza nem mesmo pela locomoção deles, os auxílios são precários e o que se tem é um verdadeiro descaso travestido nas falas de promoção da diversidade.

Fora que o problema do ingresso não foi de todo resolvido. Cláudia chama a atenção para os casos de entrada de estudantes não indígenas através de cotas para indígenas, resguardados pelo sistema de autodeclaração.

O peso dos compromissos e das responsabilidades que esse tem que enfrentar ao entrar na universidade para com a instituição e suas comunidades originárias é grande. Isso soma-se a um ensino médio debilitado da maioria desses estudantes. Fora os problemas decorrentes do choque cultural, moradia, alimentação e integração à UnB.

Esse evento denota a maturidade da organização e presença dos indígenas na UnB. Primeiro, o evento foi articulado por uma associação estudantil criada pelos estudantes indígenas para compartilhamento da experiência universitária. Depois, o fato de ter ocorrido no espaço do Maloca, o que demostra avanço das discussões sobre permanência na universidade.

Seu objetivo foi levantar debates com a comunidade acadêmica sobre o ingresso, permanência, e os desafios na Universidade. Além de promover a visibilidade da organização estudantil indígena e fomentar a troca de saberes e vivências dentro da UnB.

\subsection{A $3^{\text {a }}$ Semana dos Acadêmicos Indígenas}

A $3^{\text {a }}$ Semana teve duração de dois dias, foi realizado no centro de convivência indígena Maloca e foi composta de quatro Mesas de debate, uma aula pública, uma exibição de filmes, além de oficinas e diversas outras atividades culturais.

O debate se deu entorno das antigas problemáticas já conhecidas (como a questão da permanência, do racismo no campus e do ingresso) mas de forma mais amadurecida. É perceptível o desenvolvimento da organização do evento que me pareceu muito mais bem estruturado. Os estudantes que estavam na organização já estavam muito mais familiarizados com a promoção de eventos do tipo, o que trouxe dinamismo para essa edição.

Na primeira mesa de debate, Braulina Aurora, do povo Baniwa, representando a AAIUnB, começa sua fala na sua língua materna. Enfatizou a importância do papel da mulher indígena estudante, e como o assunto merece ser lidado de forma diferenciada. Aqui percebe-se como houve uma evolução nas discussões anteriores. É notável que se abriu mais espaço para problematizações outras, sendo possível inclusive a discussão de questões feministas no contexto indígena. Além disso, a estudante destacou a pauta do racismo institucional, em tom de prelúdio à Mesa "Racismo Institucional - Desafio da presença Indígena na Graduação e pós" que ocorreu no segundo dia do evento. A sua principal pauta centrou-se na inocorrência de um vestibular específico indígena que não ocorre a 3 anos, enfatizando que isso proporciona um esvaziamento de povos indígenas na universidade. 
Logo após as falas deu-se início a um momento de apresentações culturais dos povos Funil-ô que apresentaram a dança Kafurna, e dos Tikuna que encenaram o ritual da menina moça. Esse último chamou-me especial atenção pois enquanto era encenado uma indígena Tikuna ia explicando e detalhando o ritual, mostrando as dificuldades de reproduzi-lo e alertando para como ocorre nos territórios indígenas. Nesse momento comecei a encarar essas apresentações não mais como exóticas exibições de povos indígenas, mas sim de ensinamentos, de vivências exemplificadas e encenadas. $\mathrm{O}$ que ocorreu foi um momento performático e político, por trazer momentos rituais a um local de reinvindicações e demandas.

A mesa "Racismo Institucional - Desafio da presença Indígena na Graduação e Pós" contou com a presença de Felipe Tuxá, representando a AAIUnB, André Reis, da DAC-UnB, Cláudio Henrique Soares, do Decanato de Pesquisa e PósGraduação (DPP), Sandra Nascimento, do Instituto autonomia e Felipe Fritz do MPF.

Felipe Tuxá chamou atenção para a naturalização do preconceito dentro da universidade. $\mathrm{O}$ racismo permeia as relações dos estudantes indígenas com os demais estudantes e professores que muito se deve a uma pretensa ignorância por parte dos atores da agressão. Os velhos jargões e estereótipos são frequentemente acionados nessa relação, como sendo algo normal. Por mais que sejam distribuídas cartilhas que enfatizem a diversidade cultural e racial no campus todo começo de semestre, gerando uma impressão de acolhimento, na prática o respeito pautado está longe de ser concreto. Isso entra em acordo com o conceito de 'interculturalidade funcional' de Walsh, no qual a interculturalidade é quase caricata e serve mais para amenizar os efeitos da imposição de um sistema cultural sobre outro do que para gerar uma ralação de igualdade no qual se constrói a partir desse encontro uma sociedade verdade mente pluricultural. (Walsh, 2009).

Em sua fala, Felipe Tuxá deixou claro um aspecto muito interessante: esse preconceito não se deve a uma falta de conhecimento, como afirmam muitos ao serem acusados de racismo, mas sim a um conhecimento racista. Há uma necessidade de uma reformulação e abandono desse tipo de conhecimento, e isso ocorrerá na medida que mais estudantes indígenas ocupem os espaços universitários, pois parte deles a conscientização. Desta forma, conclui, "a presença faz a diferença”.

O representante do Decanato de Pesquisa e Pós-Graduação, Cláudio Henrique Soares, foi breve e sucinto em sua fala, propondo uma atitude concreta para lidar com as particularidades dos indígenas enquanto estudantes. Para ele o que deve ser feito é a institucionalização das diferenças. A partir das demandas dos estudantes, criar programas fixos que perpassem o julgo da administração vigente. Dessa forma, os alunos não ficariam à mercê da boa vontade de outros, mas sim poderão contar com um fundo institucional que garante seus direitos dentro da universidade.

A fala de Sandra Nascimento do Instituto Autonomia, focou nas falhas e atrasos da universidade enquanto instituição plural. São 13 anos de políticas públicas 
fracas, sem impacto significativo e real. Não há, afirma, políticas públicas para os indígenas na UnB, mas sim arranjos de pessoas bem-intencionadas. Apesar de passar a imagem, como já mencionado, de ser uma instituição pró diversidade, a UnB não se comporta como tal, limitando suas ações a confecção de cartilhas para distribuição na aula magna no início de cada semestre. O que se têm, ao contrário, é uma conivência institucional com a desigualdade e o racismo, uma vez que essas temáticas não entram na agenda de forma concreta da universidade.

Felipe Fritz, representando o Ministério Público Federal, começa sua fala com uma crítica ao pronunciamento de André Reis: "Não são os indígenas que tem que se adaptar à universidade, é ela que tem que acolher a diversidade." Tampouco deve ser a universidade um local de manifestação do racismo, mas sim, pelo contrário, um local onde essa problemática é revista e combatida. $\mathrm{O}$ que deve ocorrer é a instituição passar do nível da sensibilização (tal como faz quando promove cartilhas e cartazes contra o racismo) e chegar ao da conscientização (quando os direitos da pessoa são respeitados).

É exatamente nesse último aspecto que as falas se confluem. Há uma omissão institucional sobre o racismo na UnB. Todos sabem que o problema existe, é ético ir contra, porém na prática pouco se concretiza. Isso só mudará, pelo que se percebe, a partir do momento que virar pauta nas políticas da universidade considerar que a diversidade existe e nela há uma desigualdade. Fala-se da pluralidade do campus, mas ignora-se a violência que esses agentes da pluralidade sofrem. Vemos, pois, mais uma vez o exotismo sendo acionada para caracterizar esses estudantes. Enquanto deixam o campus mais diversos são bem-vindos e ganham até espaço na publicidade, mas na hora de ouvi-los, os antigos estereótipos e preconceitos ficam na frente e impedem que sejam levados a sério.

Em seguida, houve uma aula pública na parte central do ICC Norte, local de alto fluxo de pessoas durante todo dia. A aula teve como principal objetivo um manifesto: mostrar a presença indígena na universidade e quebrar certos preconceitos comuns do pensamento das pessoas que não possuem proximidade com o movimento. Nesse sentido, a primeira expositora, estudante indígena e professora no ensino básico, Daira Tukano, começou sua fala enfatizando "como se índio não pudesse pertencer a este século." O principal problema a respeito de como o branco vê o indígena está na epistemologia que o primeiro está inserido, pois esta é colonial e entende o 'índio' como, ainda, o 'selvagem'.

O próprio termo índio, apontou, é agressivo, pois carrega um conteúdo racista que vem desde o primeiro contato com os Europeus. Seguindo esta linha, ela faz uma revisão da história que nos é passada no ensino básico apontando onde e o que foi omitido quanto à verdade dos povos indígenas. Houve verdadeiros campos de concentração de extermínio indígena, que assumiram diversas formas. Genocídio não é exclusividade de uma etnia asiática, mas porque estudamos o caso da Alemanha e não entendemos o que está bem debaixo de nosso nariz? O reformatório Krenak foi parte da história do Brasil que é omitida pelos livros didáticos. A partir disso, ela expõe brevemente a trajetória do 
movimento indígena no Brasil, mostrando como o movimento é atuante desde, principalmente, a década de 50. O intuito foi evidenciar a existência desse movimento e fazer o link com a presença dos indígenas na universidade. Um entendimento melhor dessa trajetória histórica já foi dado nesse trabalho. Por fim, termina sua fala convidando os presentes a procurarem saber sobre o Acampamento Terra Livre que ocorrera na semana seguinte ao evento.

O segundo apresentador foi Porã Potiguara, estudante de engenharia florestal. Em sua fala, evidenciou mal-entendidos a respeito do que se sabe sobre os indígenas. Os povos indígenas existem a muito mais do que 500 anos, porém sua história está reduzida a partir da chegada dos europeus. Além disso, a forma como o contato é contado é permeada por uma visão colonialista que coloca o indígena como inocente. Desceram de suas caravelas e trocaram seus restos materiais pelo pau Brasil dos indígenas, é como nos é contato. Porém não se deu dessa forma, como bem nota o estudante, "foi espelhinho por espelhinho", o pau brasil não tinha valia alguma para aqueles indígenas naquele momento histórico. Percebe-se a partir disso então como a história está mal contada. Sempre leva em conta a visão do que é ou não benéfico do europeu. Outra equivocada visão é da passividade dos indígenas frente a colonização. Desde sempre houve resistência, o que não há é reconhecimento dessa. Porã destaca Zoró Baré como o primeiro preso político do Brasil. Quantos mais não tiveram e foram apagados dos registros oficiais dessa terra? Finaliza sua fala dizendo: "aprendemos tudo sobre os outros e nada sobre nós mesmo".

A última apresentação foi de Arthur Baniwa, pós-graduando em linguística. Deixou claro como os preconceitos agem na prática e permeiam o dia a dia do estudante. Em sua fala, relatou que no decorrer de sua trajetória acadêmica tanto os professores o consideravam frequentemente 'incapaz', 'burro', 'sem conhecimento', alguém que não conseguiria acompanhar o andamento do curso. Contou sobre uma vez que chegou na sala de aula e ao dizer que era indígena a professora perguntou por que ele não estava vestido caracteristicamente como tal. Aquela velha ideia de que o indígena está preso no tempo. A forma como ele percebe os outros o percebendo é sempre perpassada pelo prisma da exotização. Os problemas do estudante não são só epistemológicos, mas sim também o racismo diário, que os exclui, os desloca, e não permite uma conversa honesta.

\section{Conclusão}

A análise dos eventos promovidos pelos estudantes indígenas da UnB no campus Darcy Ribeiro nos anos 2009, 2010, 2016 e 2017 colocam em relevo os desafios vigentes para as políticas públicas que objetivam garantir o direito à educação para segmentos sociais historicamente marginalizados do ensino superior brasileiro. As dificuldades denunciadas pelos estudantes indígenas, nesses espaços, referem-se a empecilhos desde a chegada em Brasília até a relação com os docentes e outros atores da comunidade universitária. Dilemas psicológicos, tendo que enfrentar um conflito de identidade ao ter que pensar em uma lógica que nega seu conhecimento nativo; sociais ao se deparar com preconceitos; e econômicos, por não terem subsídio adequado, sendo que 
quando conseguem acessar a política institucional de auxílio estudantil em algumas oportunidades pode atrasar ou não efetivar-se.

Em muitos casos, ao ingressar na universidade, os estudantes indígenas são obrigados pela estrutura acadêmica e burocrática a adequar-se a um modo operacional de educação totalmente distinto daqueles dos seus povos de origem. O processo de aculturação, entendido como o contato e relação entre dois grupos étnicos distintos, se apresenta nessa fase de forma violenta. Para além disso, a distância geográfica da família e da terra natal são agravantes, que incidem em transtornos psicológicos e atrapalham consideravelmente $\mathrm{o}$ desempenho e integração no ensino superior.

A universidade é concebida com uma instituição necessária para o desenvolvimento da sociedade moderna que prioriza sua função de formar pessoas aptas para o mercado profissional. Para isso, a academia acaba assumindo um papel intelectualista e elitista. A UnB, especificamente, é conhecida por ser uma instituição voltada para a produção científica e tecnológica. Portanto essa tradição ocidental está bem presente em sua estruturação curricular. O corpo docente e discente, os técnicos e todos que nela atuam, estão, portanto, inseridos nessa lógica ocidental que renega tradições culturais diferenciadas.

Os eventos indígenas aqui analisados apresentam-se mediante modalidades científicas formais, dentre elas mesas redondas, conferências e grupos de trabalho. Porém, ao mesmo tempo, acionaram o caráter político-pedagógico, propiciando mobilizações indígenas ao interior da cena universitária. Portanto, foram formatados observando a idiossincrasia científica, embora não abrindo mão da politização das privações e negação de direitos.

Esses eventos constituem-se em manifestações de reafirmação política da conquista do espaço universitário que denúncia entraves e propõe mudanças. Durante os eventos, o sincretismo entre manifestações étnicas como danças tradicionais com mesas redondas denota os tensionamentos do contato intercultural propiciado pela presença indígena no ensino superior. Na perspectiva da interculturalidade crítica é viável apontar que esses eventos contribuem para repensar não apenas as estruturas políticas e institucionais da universidade, mas também a própria construção do saber. De nada adianta possibilitar (de forma ainda incipiente) a convivência entre diversas culturas se apenas uma é considerada válida.

No entanto, como aponta a vertente funcional da interculturalidade o risco é que essa inserção continue limitada a certo reconhecimento a fim de integrá-los à lógica dominante. Nessa lógica, os eventos promovidos pelos estudantes indígenas para evidenciar o ensino superior como espaço de dominação eurocêntrico ganham pertinência sociopolítica. 


\section{Referências Bibliográficas}

AGUIAR, Neuma. Observação participante e "Survey": uma experiência de conjugação. In: A Aventura Sociológica. Rio de Janeiro, Zahar, 1978, pp. 125 137.

CELLARD, André. A análise documental. In: POUPART, J. et al. A pesquisa qualitativa: enfoques epistemológicos e metodológicos. Petrópolis, Vozes, 2008, pp. 295-316.

DUARTE, Teresa. A possibilidade da investigação a 3: reflexões sobre triangulação (metodológica). Cies e-Working Paper, n. 6o, 2009, pp. 1-24.

KAHN, Marina; FRANCHETTO, Bruna. Educação indígena no Brasil: conquistas e desafios. Em Aberto, Brasília, v. 14, n. 63, 1994, pp. 5-9.

LUCIANO, Gersem. Indígenas no Ensino Superior: Novo Desafio para as Organizações Indígenas e Indigenistas no Brasil. In: SMILJANC, Maria Inês; PIMENTA, José; BAINES, Stephen. (Org.). Faces da Indianidade. 1ed. Curitiba: Nexo Design, 2009, v1, p. 187 - 202.

OLIVEIRA, Victoria; RUANO-IBARRA, Elizabeth. A AAIUnB e a Maloca: presença e diversidade indígena no campus Darcy. Trabalho apresentado no $24^{\circ}$ Congresso de Iniciação Científica. Brasília, 2017.

NIEDERAUER, Marcia. Universidade e universitários indígenas na internet: inclusões e exclusões no âmbito da representação. 2013. $303 \mathrm{f}$. Tese (Doutorado) - Curso de Doutorado em Linguística Aplicada, Instituto de Estudos da Linguagem, Unicamp, Campinas, 2013.

OLIVEIRA, João; DOURADO, Luiz.; MENDONÇA, Erasto. UnB: Da Universidade à "Universidade Modernizada". In: MOROSINI, Marília (Coord.). A Universidade no Brasil: concepções e modelos. Brasília: INEP, 2006, p. 113132.

PORTELA, Cristina. Por uma história mais antropológica: indígenas na contemporaneidade. Sociedade e Cultura (Impresso), v. 12, p. 151-160, 2009.

QUIJANO, Aníbal. Colonialidade do poder, eurocentrismo e América Latina. In: A colonialidade do saber: eurocentrismo e ciências sócias. Org: Edgardo Lander. $1^{\text {a }}$ ed. Buenos Aires: Consejo Latino Americano de Ciências Sociales CLACSO, 2005.

REIS, Jaime; EUZEBIO, Umberto. Inclusão social e educação no ensino superior indígena. Congreso Iberoamericano de ciência, tecnologia, inovação e educação. Anais. Buenos Aires, 2014

RIBEIRO, Gabriel. Eventos acadêmicos indígenas na UnB: interculturalidade na luta por direitos. Trabalho apresentado no $23^{\circ}$ Congresso de Iniciação Científica da UnB. Brasília, novembro de 2017.

RIBEIRO, Darcy. A universidade necessária. Rio de Janeiro: Paz e Terra, 1975, $313 \mathrm{p}$. 
RODRIGUES, Neuma Brilhante. Como se deve escrever a história do Brasil: uma leitura de von Martius. In: SIMPÓSIO NACIONAL DE HISTÓRIA, 24., 2007, São Leopoldo, RS. Anais do XXIV Simpósio Nacional de História História e multidisciplinaridade: territórios e deslocamentos. São Leopoldo: Unisinos, 2007. CD-ROM.

RUANO-IBARRA, Elizabeth. "MINGA" E AIR EM PERSPECTIVA COMPARADA. Formas e significados nos protestos indígenas na Colômbia e no Brasil. Tese de doutoramento apresentada ao Centro de Pesquisa e Pósgraduação sobre as Américas (CEPPAC) da Universidade de Brasília. 2013. 331 p.

SEVERINO, Joaquim Antonio. $O$ ensino superior brasileiro: novas configurações e velhos desafios. Curitiba: Editora UFPR, 2008. pp. 73-89.

SOUSA, Josicelia do Nascimento Ramos. Os Desafios dos estudantes e das instituições no convênio- FUNAI - UNB. Monografia de Especialização em Indigenismo e Desenvolvimento Sustentável) - Centro de Desenvolvimento Sustentável, Universidade de Brasília, Brasília. 2009, 85 f.

TARGINO, M. G; NEYRA, O. N. B. Dinâmica de apresentação de trabalhos em eventos científicos. Informação e Sociedade: Estudos, Paraíba, v 16, n 2, 2006.

TORO A., J. B.; WERNECK, N. M. D. Mobilização social: um modo de construir a democracia e a participação. Brasília: Ministério Amb Rec Hidr Amazon Leg, 1997.

UMBERTO, Euzébio. Realidade e desafios para a educação superior indígena na Universidade de Brasília. In: ABEP, 2012, Águas de Lindóia/SP. XVIII Encontro Nacional de Estudos Populacionais. 2012. p. 1-12.

WALSH, Catherine. Interculturalidad crítica y educación intercultural. Instituto Internacional de Integración del Convenio Andrés Bello, La Paz, 9-11 de marzo de 2009.

\section{Fontes documentais}

AAIUnB. Projeto da II Semana cultural dos povos indígenas na UnB. Brasília: Maloca. 2016. 10 páginas.

APURINÃ, Francisco; TUKANO, Francisco Sarmento; TUXÁ, Felipe. Relatoria II Semana Indígena. Brasília: Maloca. 2016. 11 páginas.

CINEP e APIB. Programação $1^{\circ}$ Congresso dos acadêmicos indígenas. Brasília: CINEP. 2009. 6 páginas.

GERVÁSIO, Suliete. Relatoria II Semana Indígena. Brasília: Maloca. 2016. 3 páginas.

LUCIANO, Gersém. Carta Circular 035/2009 CINEP. Brasília: CINEP. 2009. 2 páginas. 